\title{
Prediction of Convective Heat Transfer Coefficient and Temperature Distribution of Air-Conditioned Spaces Using Numerical Simulation
}

\author{
Hussein J. Akeiber ${ }^{1}$, Mazlan A. Wahid ${ }^{1}$, Hasanen M. Hussen ${ }^{2}$, Abdulrahman Th. Mohammad ${ }^{3}$, Bashar \\ Mudhaffar Abdullah ${ }^{4}$, Arkan.Altaie ${ }^{2}$, A. Aftab ${ }^{5}$, Raid. A. Alwan ${ }^{6} \&$ M.M.Sies ${ }^{6}$ \\ ${ }^{1}$ Department of Mechanical Engineering, University Technology Malaysia \\ ${ }^{2}$ Machine and Mechanical Department, University of Technology, Baghdad, Iraq \\ ${ }^{3}$ Baqubah Technical Institute, Middle Technical University, Baghdad, Iraq \\ ${ }^{4}$ Clinical Investigation Centre, University Malaya Medical Centre, ${ }^{13}$ th Floor Main Tower, Lembah Pantai, \\ 59100 Kuala Lumpur, Malaysia \\ ${ }^{5}$ Petroleum and Natural Gas Engineering Department, Mehran UETSZAB Khaipur Mirs, 66020 Sindh Pakistan \\ ${ }^{6}$ High-Speed Reacting Flow Laboratory, Faculty of Mechanical Engineering Universiti Teknologi Malaysia, \\ 81310 UTM Skudai, Johor, Malaysia \\ Correspondence: Hussein J. Akeiber, Department of Mechanical Engineering, University Technology Malaysia. \\ Tel: 60-1111261344, Fax: 607-556-6162. E-mail: HusseinUTM@yahoo.com.my
}

Received: October 30, 2015

Accepted: April 3, 2016

Online Published: May 17, 2016

doi:10.5539/mas.v10n8p12

URL: http://dx.doi.org/10.5539/mas.v10n8p12

\begin{abstract}
Accurate and efficient modeling of convective heat transfer coefficient (CHTC) by considering the detailed room geometry and heat flux density in building is demanding for economy, environmental amiability, and user satisfaction. We report the three-dimensional finite-volume numerical simulation of internal room flow field characteristics with heated walls. Two different room geometries are chosen to determine the CHTC and temperature distribution. The conservation equations (elliptic partial differential) for the incompressible fluid flows are numerically solved using iterative method with no-slip boundary conditions to compute velocity components, pressure, temperature, turbulent kinetic energy, and dissipation rate. A line-by-line solution technique combined with a tri-diagonal matrix algorithm (TDMA) is used. The temperature field is simulated for various combinations of air-change per hour and geometrical parameters. The values of HTCs are found to enhance with increasing wall temperatures.
\end{abstract}

Keyword: Convective flow, CHTC, Temperature field, $\mathrm{ACH}$

\section{Introduction}

Nowadays, renewable energy has attracted great attention (Abdullah et al., 2016a; Abdullah et al., 2016b; Abdullah et al., 2015a; Abdullah et al., 2015b; Salimon et al., 2014; Salimon et al., 2013). In the past, several models are developed and numerical simulations are performed to determining the convective heat exchange of buoyancy-driven flows along vertical surfaces of building structure in the presence of air-conditioning (Fohanno \& Polidori 2006). The entire building simulation models target to predict precisely the convective flow mediated temperature distribution for improved thermal management in energy efficient buildings. These techniques are developed based on sustainable building assessment tools and standards to achieve highest user satisfaction from adaptive behavior and electrical cost saving. Thus, it is necessary to develop a simplified model to readily determine the average CHTC as a function of room geometry and the heat flux density of walls.

Lari et al., 2011 combined the heat transfer of natural convection and radiation in a 2D square cavity, where the continuity, momentum, and energy equations are solved using a finite volume method to determine the temperature, velocity, and heat flux distributions inside the enclosed room volume. The simulation is performed using a broad range of Rayleigh numbers (102 to 106) and optical thicknesses (0 to100) to analyze the heat transfer and flow characteristics of the square cavity. The value of Nusselt number for radiative flow is observed to be several times higher than that of the convective one for the same Rayleigh number. Karadag 2009 correlated the radiative and convective heat transfer coefficient of a room with cool ceiling isolated from the 
floor surface. Three different room dimensions such as $(3 \mathrm{~m} \times 3 \mathrm{~m} \times 3 \mathrm{~m}),(4 \mathrm{~m} \times 3 \mathrm{~m} \times 4 \mathrm{~m})$ and $(6 \mathrm{~m} \times 3 \mathrm{~m} \times$ $4 \mathrm{~m}$ ) at $T_{c}=0-25{ }^{\circ} \mathrm{C}$, and $T_{w}=28-36{ }^{\circ} \mathrm{C}$ are selected. The ratio of radiative to convective HTC is found to enhance with increasing temperature differences. Wallenten 2001 considered a room with and without furniture to measure the CHTC at the outer ambient wall, where the windows are exposed to natural climate. The CHTC revealed an increase with the increase of temperature difference, where the vertical average in the middle of the room is chosen as reference temperature.

A flow responsive model is introduced to simulate the CHT at internal building surfaces (Beausoleil-Morrison 2002), where the algorithm controlled the convection dynamically by assigning appropriate equations to each internal surface at every time-step. A new modeling tool called ESP-r is developed to simulate the building performance (Beausoleil-Morrison 2001), which is used to demonstrate the mixed convection within mechanically ventilated rooms. An ESP-r based simulation with mixed flow model indicated a high sensitiveness of heating and cooling loads on the surface convection. For typical occupancy conditions of an office or residential building, Causone et al. 2009 evaluated the HTCs of radiant ceiling and room. In case of cooled ceiling, the total HTCs displayed a slightly higher value $\left(13.2 \mathrm{~W} \mathrm{~m}^{-2} \mathrm{~K}^{-1}\right)$ compared to the literature one $\left(11 \mathrm{~W} \mathrm{~m} \mathrm{~m}^{-2}\right.$ $\mathrm{K}^{-1}$ ). Despite much research accurate modeling of the CHT from interior vertical building surfaces subject to a uniform heat flux density remains challenging (Durmuşa \& Daloğlu 2008 and Keyyanfar et al. 2006).

This paper presents the 3D finite-volume numerical simulation of a model to predict CHTC and temperature distribution within the rooms (different geometries) with heated walls. The simulation is carried out using various combinations of air-change per hour and geometrical parameters.

\section{Model and Simulation}

\subsection{Governing Equations}

Newton's second law is used to derive the following Navier-Stokes equations to describing the incompressible fluid flow:

$$
\begin{gathered}
\frac{\partial(\rho u)}{\partial t}+\frac{\partial(\rho u u)}{\partial x}+\frac{\partial(\rho v u)}{\partial y}+\frac{\partial(\rho w u)}{\partial z}=-\frac{\partial p}{\partial x}+\mu\left[\frac{\partial^{2} u}{\partial x^{2}}+\frac{\partial^{2} u}{\partial y^{2}}+\frac{\partial^{2} u}{\partial z^{2}}\right] \\
\frac{\partial(\rho v)}{\partial t}+\frac{\partial(\rho u v)}{\partial x}+\frac{\partial(\rho v v)}{\partial y}+\frac{\partial(\rho w v)}{\partial z}=-\frac{\partial p}{\partial y}+\mu\left[\frac{\partial^{2} v}{\partial x^{2}}+\frac{\partial^{2} v}{\partial y^{2}}+\frac{\partial^{2} v}{\partial z^{2}}\right] \\
\frac{\partial(\rho w)}{\partial t}+\frac{\partial(\rho u w)}{\partial x}+\frac{\partial(\rho v w)}{\partial y}+\frac{\partial(\rho w w)}{\partial z}=-\frac{\partial p}{\partial z}+\mu\left[\frac{\partial^{2} w}{\partial x^{2}}+\frac{\partial^{2} w}{\partial y^{2}}+\frac{\partial^{2} w}{\partial z^{2}}\right]
\end{gathered}
$$

where $u, v$ and $w$ represents the stream line, lateral, and vertical velocity components, respectively; $x, y$ and $z$ signifies the corresponding directions to the velocity components; $\mu, \rho$ and $p$ are the fluid dynamic viscosity, the density, the pressure, respectively.

In Cartesian tensor notation the above equations are written as:

$$
\frac{\partial\left(\rho u_{i}\right)}{\partial t}+\frac{\partial\left(\rho u_{j} u_{i}\right)}{\partial x_{j}}=-\frac{\partial p}{\partial x_{i}}+\frac{\partial}{\partial x_{i}}\left[\left(\frac{\partial u_{i}}{\partial x_{j}}+\frac{\partial u_{j}}{\partial x_{i}}\right)\right]+S_{b j}
$$

where $i$ and $j$ represents the three spatial co-ordinates, $S_{b j}$ are the buoyancy source or sink terms, and $t$ is the time.

These conserved equations specifies the scalar properties of the flow in terms of enthalpy, temperature, turbulent kinetic energy $(\mathrm{K})$ or turbulence dissipation rate $(\mathcal{E})$. The generalized form of the scalar property $(\Phi)$ yields:

$$
\frac{\partial(\rho \Phi)}{\partial t}+\frac{\partial}{\partial x_{j}}\left(\rho u_{j} \Phi\right)=\frac{\partial J_{\Phi . j}}{\partial x_{j}}+S_{\Phi}
$$


where $S_{\Phi}$ represents a source or sink for $\Phi$ and $J_{\Phi, j}$ is the diffusion in the $j$ direction.

The scalar property flux $J_{\Phi, j}$ is related to the gradient of velocity components and scalar properties via the constitutive relation $[8]$ :

$$
J_{\Phi, j}=\frac{\mu}{\sigma_{\Phi}}\left(\frac{\partial \Phi}{\partial x_{j}}\right)
$$

where $\sigma_{\Phi}$ is the Prandt1/Schmidt number of the fluid.

\subsection{Simulation Details}

The abovementioned equations for the incompressible fluid (air) flows are simulated following an iterative method to determine the CHT within an enclosure. The conservation laws are expressed in terms of elliptic partial differential equations with three Cartesian components $(x, y, z)$ as the independent variables. The dependent variables are the three velocity components $(u, v, w)$, pressure $(p)$, temperature $(T)$, turbulent kinetic energy $(K)$ and dissipation rate $(\mathcal{E})$ of the fluid. A line-by-line solution technique combined with a tri-diagonal matrix algorithm (TDMA) is employed to compute the dependent variables [8]. A 3D block adjustment procedure is applied to preserve the continuity. The hybrid difference scheme (linear ZED) is used to the convective terms and the integrated source term, where the numerical stability is enhanced. A grid of non-uniform intervals is employed within the calculation domain for three directions with the grid nodes concentrated near the walls, inlet, and outlet grill. The no-slip boundary conditions are applied on the velocity at all walls and friction is calculated by introducing wall-function.

\section{Results and Discussion}

As aforementioned, the numerical analysis is based on finite volume method. Three dimensional unsteady air flow equations are simulated for two different geometries of internal room with heated walls. Figure 1 illustrates the dimension of the model room $(80 \mathrm{~cm} \times 60 \mathrm{~cm} \times 60 \mathrm{~cm})$ with two different air source positions for the computation of CHTC and temperature distribution of the room.

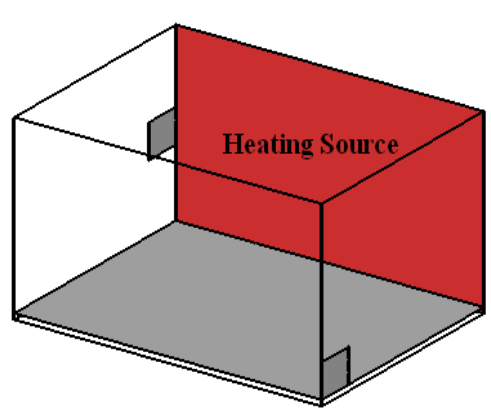

(a)

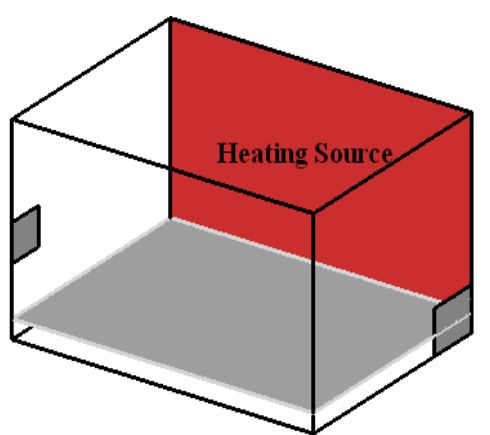

(b)

Figure 1. Schematic diagram of the two configurations (a) wall heating with near input air hole (b) wall heating with far input air hole

Figure 2 displays the temperature difference dependent variation of the CHTCs for the first model room at 5 air change per hour $(\mathrm{ACH})$ with different wall temperatures. The values of CHTCs are found to increase with increasing wall temperatures following a new correlation given by:

CHTC $=0.163\left(\mathrm{~T}_{\text {beater }}-\mathrm{T}_{\text {trulet }}\right)^{1-196}$ 


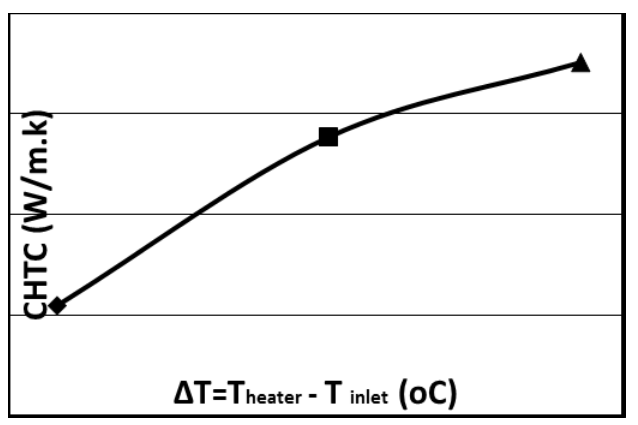

Figure 2. Film coefficient with different inlet temperature at $5 \mathrm{ACH}$ for the first configuration

Figure 3 demonstrates the influence of $\mathrm{ACH}$ on the temperature profile, which is considered at the position of $x=$ 0.0225 and $x=0.5725 \mathrm{~m}$ for two different room geometries, respectively. For the first configuration (Figure 1(a)), the warm air can reach the lower levels $(x=0.0225 \mathrm{~m})$ at temperature $21{ }^{\circ} \mathrm{C}$ with $20 \mathrm{ACH}$ (Figure 3). The temperature in the central region $(x=0.5725 \mathrm{~m})$ at $5 \mathrm{ACH}$ revealed low values $\left(19^{\circ} \mathrm{C}\right)$, where the temperature distribution is determined to be close to the end of region at $20 \mathrm{ACH}$ (Figure 4).

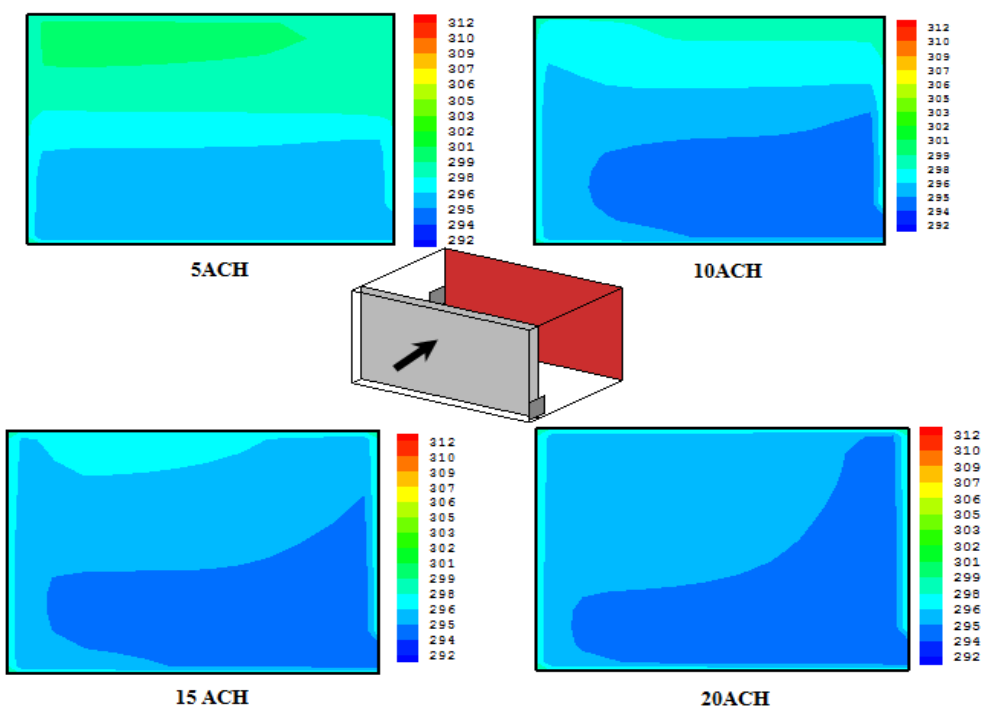

Figure 3. Temperature distribution for the first configuration at different flow rate with $x=0.0225$
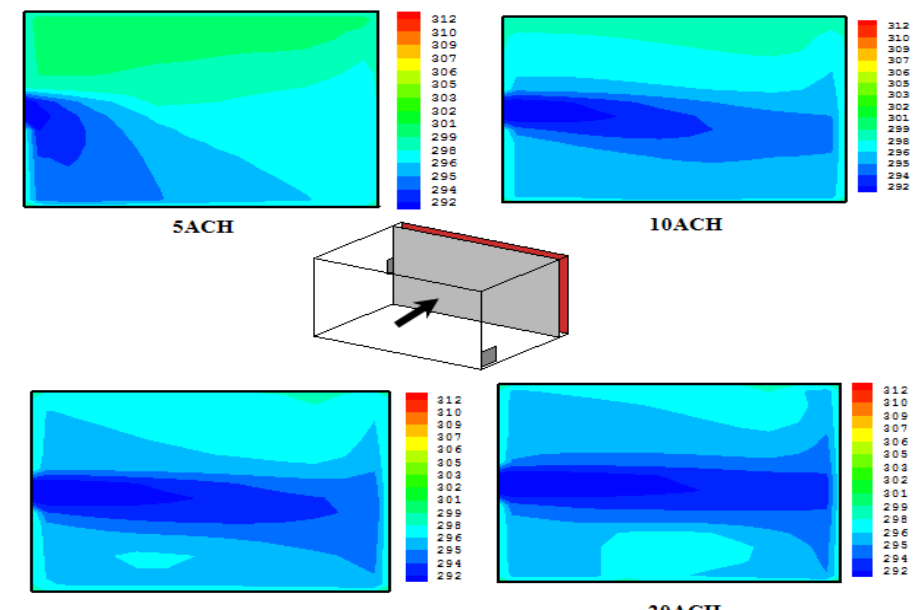

$15 \mathrm{ACH}$

20ACH

Figure 4. Temperature distribution for the first configuration at different flow rate with $x=0.5725$.

For air source position far away from the heated wall (Figure 1(b)), the range of temperature within the region of 
$x=0.0225$ is observed to vary in the range of $19-33{ }^{\circ} \mathrm{C}$ at $5 \mathrm{ACH}$, and $19-25{ }^{\circ} \mathrm{C}$ at $20 \mathrm{ACH}$ as shown in Figure 5. Conversely, only the middle portion of the region $(x=0.5725 \mathrm{~m})$ at $20 \mathrm{ACH}$ is closed to the initial temperature condition of $21{ }^{\circ} \mathrm{C}$. Furthermore, the temperature distribution near the edges is ranged between 24 to $26{ }^{\circ} \mathrm{C}$ (Figure 6).
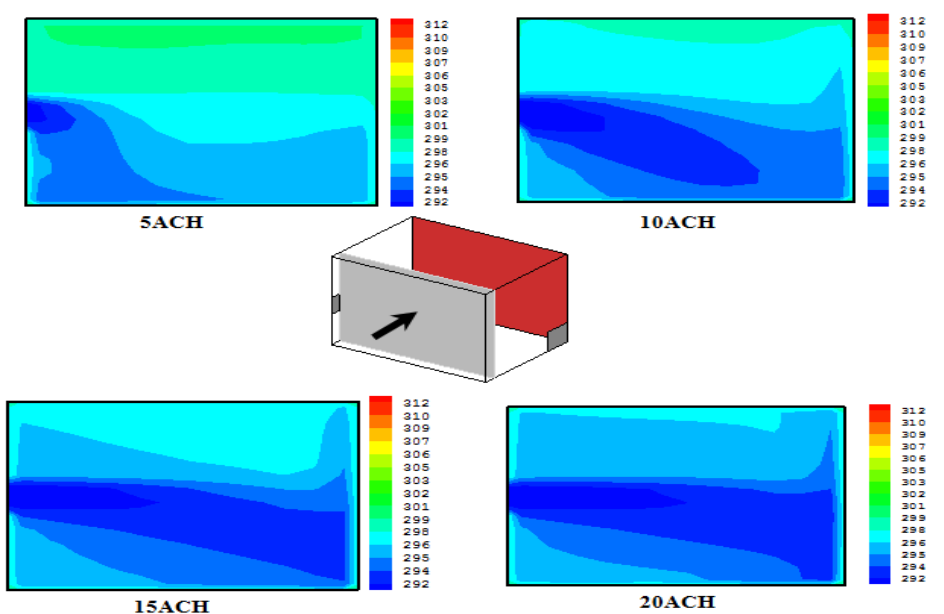

Figure 5. Temperature distribution for the second configuration at different flow rate with $x=0.0225$
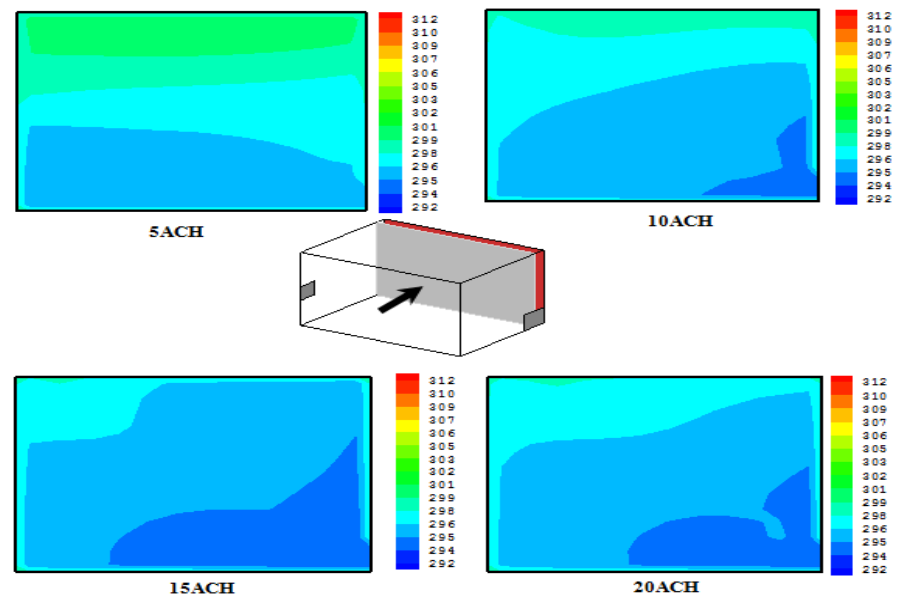

Figure 6. Temperature distribution for the second configuration at different flow rate with $x=0.5725$

\section{Conclusions}

We developed a model and carried out 3D finite-volume numerical simulation to predict the CHTC and temperature distribution of air flow inside a room with heated walls. The temperature field is determined for different combinations of ACH. Two different room configurations are chosen to determine their influence on the CHTCs and temperature distribution inside the volume. The line-by-line solution technique, and no-slip boundary condition together with TDMA is used for simulation. The values of HTCs are found to enhance with the increase of wall temperatures following a new power law correlation. The room geometry is demonstrated to play a key role in deciding the HTCs and temperature distribution inside. It is established that the present model and simulation method may be used to predict the flow patterns in addition to the internal and external CHTCs for complex air flows in building architecture useful for thermal management and adaptive user satisfaction.

\section{Acknowledgment}

The financial supports from the Malaysian Ministry of Higher Education (MOHE), Iraqi Ministry of Higher Education (MOHE) and Universiti Teknologi Malaysia are gratefully acknowledged. 


\section{References}

Abdullah, B. M., Huri, H. Z., \& Hairunisa, N. (2015b). Hydrolysis, Separation and Purification of Fatty Acids for Bioproducts: Saturated and Unsaturated Fatty Acids Preparation using Potassium Hydroxide and Urea Complex Fractionation. Lambert Academic Publishing, Saabrücken, Germany.

Abdullah, B. M., Huri, H. Z., \& Yousif, E. (2015a). Biolubricant base oil synthesis and its applications: Pharmaceutical and industrial applications based on environmentally friendly. Lambert Academic Publishing, Saabrücken, Germany.

Abdullah, B. M., Yusop, R. M., Salimon, J., Derawi, D., \& Ahmed, W. A. (2016a). Epoxidation Synthesis of Linoleic Acid for Renewable Energy Applications. The Malaysian Journal of Analytical Sciences, 20 , 131-141.

Abdullah, B. M., Zubairi, S. I., Huri, H. Z., Hairunisa, N., Yousif, E., \& Basu, R. C. (2016b). Polyesters based on linoleic acid for biolubricant basestocks: Low-temperature, Tribological and Rheological properties. Plos One, 11(3), e0151603.

Beausoleil-Morrison, I. (2001). An algorithm for calculating convection coeffcients for internal building surfaces for the case of mixed flow in rooms. Energy and Buildings, 33, 351-361

Beausoleil-Morrison, I. (2002). The adaptive simulation of convective heat transfer at internal building surfaces. Building and Environment, 37l, 791-806.

Causone, F., Corgnati, S. P., Filippi, M., \& Olesen, B. W. (2009). Experimental evaluation of heat transfer coefficients between radiant ceiling and room. Energy and Buildings, 41, 622-628.

Durmuşa, A., \& Daloğlu, A. (2008). Numerical and Experimental Study of Air Flow by Natural Convection in a Rectangular Open Cavity: Application in a Top Refrigerator Experimental. Heat Transfer, 21, 281-295.

Fohanno, S., \& Polidori, G. (2006). Modelling of natural convective heat transfer at an internal surface. Energy and Buildings, 38, 548-553.

Karadag, R. (2009). The investigation of relation between radiative and convective heat transfer coefficients at the ceiling in a cooled ceiling room. Energy Conversion and Management, 50, 1-5.

Keyvanfar, A., Shafaghat, A., Abd Majid, M. Z., Lamit, H. B., Ali, K. N. B., Ahmad, M. H., \& Ghoshal, S. K. (2016). Methods for Adaptive Behaviors Satisfaction Assessment with Energy Efficient Building Design. Renewable and Sustainable Energy Reviews, 57, 250-256.

Lari, K., Baneshi, M. G., Nassab, S. A., Komiya, A., \& Maruyama, S. (2011). Combined heat transfer of radiation and natural convection in a square cavity containing participating gases. International Journal of Heat and Mass Transfer, 54, 5087-5099.

Salimon, J., Abdullah, B. M., Yusop, R. M., \& Salih, N. (2013). Synthesis and optimization ring opening of monoepoxide linoleic acid using $p$-Toluenesulfonic acid. SpringerPlus, 2, 429.

Salimon, J., Abdullah, B. M., Yusop, R. M., \& Salih, N. (2014). Synthesis, reactivity and application studies for different biolubricants. Chemistry Central Journal, 8, 16.

Wallenten, P. (2001). Convective heat transfer coefficients in a full-scale room with and without furniture. Building and Environment, 36, 743-751.

\section{Copyrights}

Copyright for this article is retained by the author(s), with first publication rights granted to the journal.

This is an open-access article distributed under the terms and conditions of the Creative Commons Attribution license (http://creativecommons.org/licenses/by/3.0/). 